\title{
A Water Scarcity Evaluation Model for Sustainability of Countries
}

\author{
Meng Li \\ School of Electrical Engineering, North China Electric Power University, Baoding 071000, China \\ 295273953@qq.com
}

Keywords: AHP; the Entropy model; Product integration method; DPSIR.

\begin{abstract}
In order to evaluate the ability of a region to provide fresh water to meet the need of its residents. We describe metrics in three aspects: the produce of water, the consumption of water and extra aspect. Moreover, each aspect is subdivided into several secondary indexes based on Food and Agriculture Organization of the United Notions. First, Analytic Hierarchy Process (AHP) Model is established to determine the weight of each indicator and evaluate the water scarcity. Then the Entropy model is built to overcome weakness of excess subjective factors in AHP. By using Product integration method to combine two models, we determine the final indicators weights and apply those weights into the DPSIR model to calculate CEI of 18 main countries and classify those into 4 levels. As far as CEI is concerned, the bigger, the better. Finally we take Kazakhstan as an example to analyze the reasons of the water scarcity and future fresh water situation in this country.
\end{abstract}

\section{Introduction}

The world runs on water. Clean reliable water supplies are vital for industry, agriculture and energy production. Yet the world's water systems face formidable threats. More than a billion people currently live in water-scarce regions, and as many as 3.5 billion could experience water scarcity by 2025[1]. The water scarcity has become one of the most pressing issues in the world. It is critical to make a plan to proving water scarcity, and we face a problems: Taking dynamic nature of factors that affects both supply and need into consideration, develop a model to measure the ability of a region to provide clean water.

\section{Two Models for the Weight of Multiple Indicators}

2.1 Model One: Analytic Hierarchy Process (AHP).

\section{The three-hierarchy structure}

The four hierarchy structure which contains criteria level [2, 3] and alternative level is shown in table 1. 
Table 1 . The four hierarchy structure of our model

\begin{tabular}{|c|c|c|c|}
\hline Goal & Criteria I & Criteria II & Alternatives \\
\hline \multirow{12}{*}{$\begin{array}{c}\text { The } \\
\text { scarcity of } \\
\text { water } \\
\text { resources }\end{array}$} & \multirow{4}{*}{$\begin{array}{c}\text { The } \\
\text { generation } \\
\text { of water }\end{array}$} & Rainfall & Long-term average precipitation in depth \\
\hline & & Surface & Surface water produced internally \\
\hline & & water & $\cdots$ \\
\hline & & $\begin{array}{l}\text { Underground } \\
\text { water }\end{array}$ & $\begin{array}{c}\text { Groundwater produced internally } \\
\qquad . .\end{array}$ \\
\hline & \multirow{3}{*}{$\begin{array}{c}\text { The } \\
\text { consumption } \\
\text { of water }\end{array}$} & \multirow{2}{*}{ Agriculture } & Cultivated area (arable land + permanent crops) \\
\hline & & & $\cdots$ \\
\hline & & Industry & Industrial water withdrawal \\
\hline & \multirow{5}{*}{ Others } & \multirow{2}{*}{ Population } & Total area \\
\hline & & & $\cdots$ \\
\hline & & \multirow{2}{*}{ Economy } & Gross Domestic Product (GDP) \\
\hline & & & $\cdots$ \\
\hline & & Others & $\begin{array}{l}\text { Total internal renewable water resources per capita } \\
\qquad . .\end{array}$ \\
\hline
\end{tabular}

\section{Obtain the index weight}

- Determine the judging matrix

We use the pairwise comparison method and one-nine method to construct judging matrix $A=\left(a_{i j}\right)$.

- Calculate the eigenvalues and eigenvectors

The greatest eigenvalue of matrix $\mathrm{A}$ is $\lambda_{\max }$ and corresponding eigenvector which has been normalized is $w$ which satisfies the expression:

$A w=\lambda w$

- Do the consistency check

- Calculate the Combination eigenvectors

$w^{(3)}=W^{(3)} w^{(2)}$

Where $w^{(2)}$ denotes the weight of the criteria level to the goal, $W^{(3)}$ denotes weight of alternative levels to the criteria level.

When all judging matrix pass the consistency check, we could gain the combination eigenvectors of alternatives level to the goal.

\subsection{Model Two: the Method of Entropy.}

On account of subjectivity of AHP, we introduce the method of entropy [4] which is more objective. The principle of entropy method stats that, subject to precisely stated prior data, the probability distribution which best represent the current state of knowledge is the one with largest entropy. Apply indicators which weights have been recalculate into entropy method, there are mainly five steps:

- Calculate the entropy for the indicator $i^{\text {th }}$ :

$$
H_{i}=-\frac{1}{\ln n} \sum_{j=1}^{n} f_{i j} \ln f_{i j}(i=1,2, \cdots, m ; j=1,2, \cdots n)
$$

Where $f_{i j}=\frac{r_{i j}}{\sum_{j=1}^{n} r_{i j}}\left(\right.$ when $\left.f_{i j} \leq 0, f_{i j} \ln f_{i j}=0\right) . r_{i j}$ is the indicators After standardization.

- Determine the weight for each indicator:

$W_{i}=\frac{1-H_{i}}{m-\sum_{i=1}^{m} H_{i}} i=1,2, \cdots m$

\subsection{Model Combination.}

AHP is a subjective method, it largely depends on artificial scoring; Entropy is an objective method, it all depend on data. To comprehensively consider the effect of subjective and objective factors, we adopt linear weighted method. 


\section{Product integrated weighting method:}

Multiply two weights of indicator $x_{j}$ from AHP and Entropy method and do the normalized processing:

$$
w_{j}=\frac{a_{j} b_{j}}{\sum_{i=1}^{m} a_{i} b_{i}}(j=1,2, \cdots m)
$$

Where $a_{j}, b_{j}$ are the weight of indicator $x_{j}$ from AHP and the method of entropy separately.

We have confirmed the weighting coefficient of 27 indicators in the evaluation system primarily, then we select 17 indicators with larger weighs from 27 initial indicators to be the main indicators and recalculate the weights which will be applied in the future work.

\section{Results}

By recalculating the weights of 17 indicators, the comprehensive weight of each indicator is shown in table 2:

Table 2. The weight comparison among the models

\begin{tabular}{|c|c|c|}
\hline The ranking of weight & indicator & weight \\
\hline 1 & $\begin{array}{l}\text { Industrial water withdrawal of total } \\
\text { water withdrawal }\end{array}$ & 0.1968 \\
\hline 2 & Total renewable groundwater & 0.1321 \\
\hline 3 & Human Development Index (HDI) & 0.1075 \\
\hline$\ldots$ & $\ldots$ & $\ldots$ \\
\hline 15 & $\begin{array}{l}\text { Agricultural water withdrawal of total } \\
\text { renewable water resources }\end{array}$ & 0.0168 \\
\hline 16 & Cultivated area & 0.0097 \\
\hline 17 & $\begin{array}{l}\text { Water resources: total external } \\
\text { renewable }\end{array}$ & 0.0096 \\
\hline
\end{tabular}

\section{The Evaluation of Regional Water Scarcity under the DPSIR Framework}

\section{DPSIR analysis approach}

The evaluation framework of the water scarcity based on the DPSIR model which contains five parts: driver, pressure, state, impact and respond. By referring the standard definitions and online expert's thoughts about the indicators we collected, we divided multiple indicators into five categories [5].

Driver: An anthropogenic activity that may have an environmental effect. Drivers produce a series of pressures and are quantified by aggregated data, e.g., Cultivated area, Population density etc.

Pressure: The direct effect of the driver. Pressures form manifestation of the effects the Driving Forces have on the the water scarcity. Agricultural could be considered as pressures.

State: The condition of the water scarcity resulting from both natural and anthropogenic factors (e.g. Total internal renewable water resources per capita, Agricultural water withdrawal etc.).

Impact: The effect upon human well beings.

Response: The measures taken to improve the state of the water scarcity.

\section{The weight of the indicators in the DPSIR framework}

Based on the AHP model and the method of Entropy, we have got the weights of indicators which are distributed into D, P, S, I, R those five comprehensive factors.

\section{Calculate comprehensive factors}

The contribution rate of $\mathrm{D}, \mathrm{P}, \mathrm{S}, \mathrm{I}, \mathrm{R}$ those five comprehensive factors to the comprehensive evaluation index of the water scarcity is different, as well as the influence of the second indicators on each comprehensive factor. So we use the comprehensive index method to calculate the value of comprehensive factors [6]. 


$$
\begin{aligned}
& D=\sum_{i=1}^{n} W_{D i} X_{D}, P=\sum_{i=1}^{n} W_{P i} X_{P}, S=\sum_{i=1}^{n} W_{S i} X_{S i} \\
& I=\sum_{i=1}^{n} W_{I i} X_{I i}, R=\sum_{i=1}^{n} W_{R i} X_{R i}
\end{aligned}
$$

Where: $X_{i}$ is the value of indicators $i$ after standardized, $W_{i}$ is the weight of indicator $i$ which express the importation of the main indicators to the comprehensive evaluation index of water scarcity.

Calculate the comprehensive evaluation index

$$
C E I=\frac{S^{W S} \times R^{W R}}{D^{W D} \times P^{W P} \times I^{W I}}
$$

Where $C E I$ is the comprehensive evaluation index which measure the ability of a region to provide clean water to meet the needs of its population. The bigger value of the comprehensive evaluation index is, the better ability of a region to provide clean water is.

\section{Results}

The comprehensive evaluation value which shows the ability of a region or country to provide the fresh water to meet the needs of its population is shown in table 3:

Table 3. The values of comprehensive evaluation indexes in 18 typical countries

\begin{tabular}{|c|c|c|}
\hline $\begin{array}{c}\text { Ranking of the water } \\
\text { producing ability }\end{array}$ & Country & CEI \\
\hline 1 & Germany & 0.2387 \\
2 & Canada & 0.2254 \\
3 & United States of America & 0.2189 \\
\hline 4 & India & 0.2042 \\
\hline 5 & China & 0.1878 \\
\hline$\ldots$ & $\ldots$ & $\ldots$ \\
\hline 12 & Afghanistan & 0.1221 \\
\hline$\ldots$ & Kazakhstan & 0.122 \\
\hline 18 & $\ldots$ & $\ldots$ \\
\hline
\end{tabular}

By referring to the method of dividing the situation of the water scarcity, we make a connection with the comprehensive evaluation and the level of the water scarcity, determine the Classification threshold of each level which is applied to evaluate the water scarcity in specific region.

We referring the data from Vital Water Graphics to evaluate the accuracy of our results and take Kazakhstan as an example, the threshold of Kazakhstan 0.122 is between 0.12 and 0.13 is be regarded as relative lack of water.

The relationship between main indicators of the water scarcity and the Seasonal and uncertainty indicators are concluded and discussed in DPSIR model, for example the change of seasonal indicators such as the decrease of precipitation in Winter which is concluded into State will reduce the supply and decrease the comprehensive evaluation index of the water scarcity.

Additionally, there may be some temporal hysteresis effect between DPSIR sectors. For instance, changes in a certain sector (e.g. State or Impact) are caused by other sectors (e.g. Driver or Pressure) that work over a certain amount of time. Therefore, further studies relative to temporal hysteresis effect between DPSIR sectors are required in order to obtain a more appropriate assessment of the interaction between DPSIR sectors. 


\section{References}

[1] http://www.wri.org/our-work/topics/water

[2] http://www.fao.org/nr/water/aquastat/water_res/index.stm

[3] Saaty, Thomas L.; Peniwati, Kirti (2008). Group Decision Making: Drawing out and Reconciling Differences. Pittsburgh, Pennsylvania: RWS Publications. ISBN 978-1-888603-08-8.

[4] Dahiya S, Singh B, Gaur S, et al. Analysis of groundwater quality using fuzzy synthetic evaluation[J]. Journal of Hazardous Materials, 2007, 147(3): 938-946

[5] European Commission. Common implementation strategy for the Water Framework Directive (2000/60 EC)

[6] Jiquan Zhang, kunpeng Yi, Hiroshitani, et al. Ecological security assessment of Baishan City in Jilin Province based on DPSIR [J]. Chinese Journal of Applied Ecology, Jan. 2011, 22(1); 189-195 